\title{
ESTUDO DO VALOR PROTÉICO DE ALGUNS PRODUTOS COMERCIAIS DA COZINHA MACROBIÓTICA *
}

\author{
Maria Josefina Leuba Salum - \\ Leda Ulson Mattos - \\ Hisako Shima -
}

SALUM, MJ .L. ; MATTOS, L.U.; SHIMA, H. - Estudo do valor protéico de alguns produtos comerciais da cozinha macrobiótica - Rev. Esc. Enf. USP 10 (1): $163 \cdot 174-1976$.

Com o intuito de estudar o valor protéico de alguns produtos utilizados na dieta macrobiótica, elaboramos um estudo experimental em ratos albinos machos. Determinamos os Indices de Eficiência Protéica e de Conversäo Alimentar e a curva de crescimento dos animais alimentados com ume mistura de arroz integral com missô (9:1), Muasli (produto à base de cereal usado como sobremesa) e leite de cereais (utilizado na alimentação infantil), comparando-os com a caseina. Resultados obtidos indicaram que a mistura arroz/missô apresenta valor protéico comparável à da caseina enquanto os demais produtos estudados revelaram-se significativamente inferiores à mesma.

\section{I - INTRODUÇÃO}

A filosofia macrobiótica, largamente difundida no Oriente e introduzida há alguns anos no Ocidente, tem levado a indagaçőes frequentes relativas ao valor nutricional da dieta macrobiótica.

Não se conhecem estudos realizados com os alimentos macro-

- Trebalho realizado pelos alunos do Curso de Greduaçäo em Enfermagem da

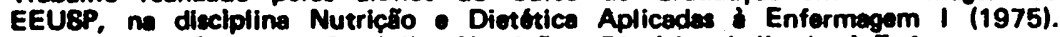

- Auxillares de Enaino de Disciplina Nutriçóo Dietética Aplicadas a Enfermagem EEUSP.

- Profeser Livre-Docente de Disciplina Nutricão e Dietética Aplicadas à Enfermagem - EEUSP. 
bióticos. Sherlock, (1967), relata um caso de uma paciente adepta da filosofia macrobiótica e que adquiriu'escorbuto apóster se alimentado da dieta macrobiótica durante 8 meses.

OHSAWA| (1972), em seu livro Macrobiotica Zen descreve o que é a filosofia macrobiotica e detem-se especificamente nas recomendações alimentares determinadas pela filosofia. A emergência desta ocorreu em função da interpretação que o autor deu a Filosofia da Modicina do Extromo Oriente. $O$ autor descreve a sua terapêutica colocando as condições para se seguir o regime macrobiótico.

Acredita-se que toda doença, infelicidade, crime e castigo resultam da má conduta, isto é, uma conduta que violenta a Ordem do Universo. A natureza é responsável pelo restabelecimento fisiológico do organismo seguindo-se quatro princípios utilização de alimentos naturais, abstenção de drogas, abstenção de cirurgia e eliminação da inatividade. Propz̃e o seguinte para iniciar-se na dieta macrobiótica, que trará ao homem saúde e felicidade ausência de fadiga, bom apetite (no sentido de que qualquer alimento deve ser saboroso e apetitoso), sono profundo, boa memória, bom humor, rapidez e dinamismo de raciocínio e de execução, compreensão total da justiça. Para o autor justiça $=$ saúde $=$ discernimento supremo $=$ unicidade $=$ infinito = Satori (convição tangivel e lógica a que o homem chegou, corpo e alma no Reino da Liberdade, da Felicidade e da Justiça). Além disso é imprescindivel que se tenha fé.

No seu livro, Ohsawa descreve os princípios dietéticos e meios de applicą̧ão dos alimentos macrobióticos, o que se resume a seguir. A dieta macrobibtica baseia-se sobretudo na utilização de cereais integrais, verduras da estação vigente, no cozimento metódico dos alimentos, em reduzir-se a ingestão de alimentos de origem animal $e$ de açucar, na boa mantigacão (cada porção deve ser mastigada no mínimo 50 vezes) e na redução da ingestão de líquidos (250 cc por dia). A escolha dos alimentos e líquidos da dieta baseia-se na teoria Yin-Yang. Yin é a força centrífuga e Yang a força centrípeta, que produzem fenômenos físicos individualmente. São forças antagónicas $e$ complementares $O s$ vegetais e verduras são $Y$ in ao passo que os alimentos animais e cereais são Yang. $\mathrm{Na}, \mathrm{H}, \mathrm{As}, \mathrm{Li}, \mathrm{Mg}$ são Yang e os outros, sobretudo $K$ são Yin. As vitaminas A,DK, são Yang e a vit $C$ é Yin.

Tudo deriva da proporção Yin - Yang (1: 5). Os alimentos mais 
Yin devem ser utilizados em menor proporção que os Yang. $O$ tempero deve ser feito com gomashio (gergelim e sal torrado moído) ou molho de soja (shoyu). Os cereais, alimentos principais, devem constituir $60 \%$ da dieta.

Os alimentos de origem animal são tidos como antifisiológicos, impedindo o desenvolvimento das faculdades cerebrais. A carpa é um dos alimentos de origem animal permitidos e mais largamente consumidos.

George Ohsawa ainda descreve regras de cozinha, que incluem o preparo dos alimentos para o cozimento e reitera a importância de utilizar cereais e de boa mastigacão.

O livro é constituido com uma série de apêndices que trazem relatos do próprio autor e de outros, em relação a alguns aspectos da dieta.

Tendo em vista a inexistência da verificação do valor protéico dos alimentos macrobióticos, especialmente daqueles que são produzidos pelas Assoiações Macrobióticos, portanto, não industrializados, resolveu-se elaborar um estudo com o seguinte objetiva determinar o índice de eficiência protéica e de conversão alimentar de alguns produtos macrobióticos e a curva de crescimento de animais alimentados com os mesmos.

Nossa intenção não é verificar a validade da dieta macrobiótica, mas apenas estudar o valor protéico de alguns alimentos nela utilizados.

Selecionamos para tanto o arroz integral que associamos com o Missô (pasta de soja), o leite de cereais, que segundo a Associação Macrobiótica de São Paulo é utilizado na alimentação infantil e o Muasli, um produto à base de cereais, ingerido como sobremesa.

\section{MATERIAL E MÉTODOS}

\section{- Material}

- Animais de experiência - foram utilizados 24 ratos (Rattus norwegicus albinus) Wistar, machos, recém desmamados, obtidos no Biotério Central da Faculdade de Medicina da USP. Os animais foram divididos ao acaso em 4 grupo de 6 animais, de forma que o peso médio fosse aproxima- 
damente o mesmo em todos os grupos.

- Caseína (") - conterido $74,77 \%$ de proteína.

- Leite de cereais ("') - contendo 10,93\% de proteína.

- Muashi ("') - contendo $11,13 \%$ de proteína.

- Mistura de arroz integral com misso ("7) - ( 9 1), contendo 7,14\% de protefna.

- Dietas - foram cauculadas de modo a fornecer $6 \%$ de proteína e aproxima. damente 380 calorias $/ 100 \mathrm{~g}$ de dieta. 
- Cagolna a 6\% (Dieta I)

\begin{tabular}{|c|c|c|c|}
\hline Alimentos & Oramas & Calorian & Protel me \\
\hline Casefina & 8,0 & 25,2 & $6 \mathrm{R}$ \\
\hline Malzena & 79,6 & 285,0 & $=$ \\
\hline 6100 & 6,0 & 55,8 & - \\
\hline oleo de Pl cado de bacal hau & 1,6 & 14,9 & $=$ \\
\hline Bais Minerala & 3,2 & - & - \\
\hline Yiteninas & 1,6 & - & $=$ \\
\hline TOTAL & $100, \dot{0}$ & 380,9 & 6 \\
\hline
\end{tabular}

- Mistura de arroz integral o missô (Dieta II)

\begin{tabular}{|c|c|c|c|}
\hline & Gramas & Calorias & Proteínas \\
\hline Miatura & 83,7 & 296,3 & $6,0 \times$ \\
\hline Mnizena & 3,9 & 14,0 & \\
\hline 0100 & 6,0 & 55,8 & \\
\hline Oloo de flgado de bacalhau & 1,6 & 14,9 & \\
\hline Saia Mineraio & 3,2 & $=$ & \\
\hline Vitani nas & 1,6 & - & \\
\hline TOTAL & 100,0 & 381,0 & 6,0 \\
\hline
\end{tabular}


- Muaw11 a 6\% (Dieta III)

\begin{tabular}{|c|c|c|c|c|c|}
\hline Ingredienten & Gramas & $\cdot$ & Calorian & ' & Protelna. \\
\hline Muas 11 & 53,9 & & 188,7 & & $6 x$ \\
\hline Maizena & 33,7 & & 120,6 & & \\
\hline Oleo & 6,0 & & 65,8 & & \\
\hline Oleo de fígudo de bucalhau & 1,0 & & 14,9 & & \\
\hline Saie Minerala & 3,2 & & - & & \\
\hline Vitaminine & 1,6 & & $=$ & & \\
\hline TOTAL, & 100,0 & & 380,0 & & $6 \mathrm{~g}$ \\
\hline
\end{tabular}

- Loite de Cereaira 6\% (Dieta IV)

\begin{tabular}{|c|c|c|c|c|c|c|c|}
\hline & Ingrediontes & $\therefore$ & Grama & ' & Calorias & 1 & Protelnas \\
\hline & Leite de Cereaia & ' & 54,9 & ' & 199,1 & $\therefore$ & $6 g$ \\
\hline & Maizena & 1 & 32,4 & 1 & 117,1 & 1 & \\
\hline & $01 \bullet 0$ & 1 & 6,0 & 1 & 56,8 & 1 & \\
\hline \multirow[t]{4}{*}{$01 \bullet 0$ de } & Ifrado bacal hau & ' & 1,6 & $\therefore$ & 14,8 & 1 & \\
\hline & Sate Mineraite & 1 & 3,2 & 1 & - & 1 & \\
\hline & Vitaminan & 1 & 1,6 & 1 & $=$ & 1 & \\
\hline & TOTAL & & 100,0 & & 379,0 & & $6_{8}$ \\
\hline
\end{tabular}


- Dosagem de Nitrogênio nos alimentos - utilizamos o método de KJEDAHL, modificado por ALBANESE (1963).

- Procedimentos experimentais - os animais foram mantidos em gaiolas individuais, em temperatura ambiente de 230C. Recebem água e alimento ad libitum, durante um período de 28 dias. 0 grupo controle recebeu a dieta I e cada grupo experimental, as demais (II, III e IV).

- Colota de dados - os animais e o alimento ingerido foram pesados em dias intercalados. Com dados assim, obtidos calculamos o PER (índice de Eficiência Protéica), ICA (ínidice de Conversão Alimentar) e Retas de regressão de crescimento dos animais.

- Anślise eotatistice - foi utilizado o teste de Student no nível de signifi cância de $1 \%$.

\section{RESULTADOS E COMENTÁRIOS}

$\mathrm{Na}$ tabela I colocamos os resultados relativos ao ganho de peso por rato (g/dia) alimento e proteína ingeridas por rato (g/dia), PER e ICA dos diferentes grupos estudados.

Para melhor visualizar o ganho ponderal dos diferentes grupos, calculamos as retas de regressão de crescimento dos animais nos diferentes grupos, e as apresentamos na figura 1.

Analisando a tabela I, verificamos que a mistura arroz-misso na proporção 9:1, revelou alto valor protéico, sendo o seu PER e ICA similares aos do grupo controle. A quantidade dos dois alimentos utilizados năo é especificamente recomendada na dieta macrobióticas mas foram associados na referida proporção lovando-se em conta a alta porcentagem de sal que contém o missô. Associaçð̌es com maiores quantidades de missô tornaria o seu uso inviável na alimentação humana.

Como recomenda OHSAWA (1972), o missô, juntamente com o môlho e queijo de soja, deve ser utilizado diariamente, pois substitue a manteiga, o queijo de origem animal e a margarina. Portanto, o seu uso 
associado do arroz integral é altamente recomendável.

Quanto ao Muashi e Leite de Cereais, revelaram ser significativamente inferiores ao grupo controle, e até mesmo à mistura arroz-missô.

Conforme comentamos anteriormente, os cereais constituem a base da dieta macrobibtic e como cita OHSAWA (1972), representa $60 \%$ do total de alimento ingerido.

O Muashi sendo utilizado apenas como sobremesa, não seria tão prejudicial, uma vez que outros alimentos da dieta complementam o seu valor nutritivo.

No entanto, quanto ao leite de cereais, a situação difere, pois como já nos referimos, e usado na alimentação infantil em substituição ao leite animal.

Assim, sendo o seu valor protéico significativamente inferior à da caseína, não constitue um alimento adequado como fonte protéica exclusiva, principalmente se considerarmos o intenso crescimento que ocorre durante $a$ infância.

\section{CONCLUSÕES}

- a associação de arroz integral ao missô na proporção de 9:1, resulta num valor protéico bastante alto, comparável ao da caseína.

- o valor protéico do muashi e leite de cereais é significativamente inferior à da caseína; assim, o leite de cereais não $c$ um alimento adequado à alimentaçăo infantil.

SADUMb M.J.L; MATTOS, L.U. \& SHIMA, H. - Proteic value study of some macrobiotic comercial products. Rev. Esc. Enf. USP, 10 (1): $163-174-1976$.

Aiming to study proteic value of some dietary products used in macrobiotic diet, the authors performed an experiment on male albino rats. Protein Efficiency and Food Conversion Index were determined 
as well as growth curve of animals fed with unpolished rice and missô mixture (9:1), Muasli (a cereal based dessert) and cereal milk (utilized in child food) and were compared to casein. Results obtained indicated that rice/missô mixture present a proteic value compaired to that of casein whereas other products that were studied showed a significant inferior value.

\section{REFERENCIAS BIBLIOGRÅFICAS}

ALBANESE, A.A. - New methods of nutritional biochemistry. New York, Academic Press, 1963. v. 1, p.84.

OHSAWA, G. - Macrobiótica Zen 3a ed. Porto Alegre, Gráfica Editora Nação, 1972. 182p.

SHERLOCK, P.S. \& ROTHSCHILD, E.O. - Scurvy produced by a Zen macrobiotic diet. JAMA, 199 (11): 130-134, 1967. 


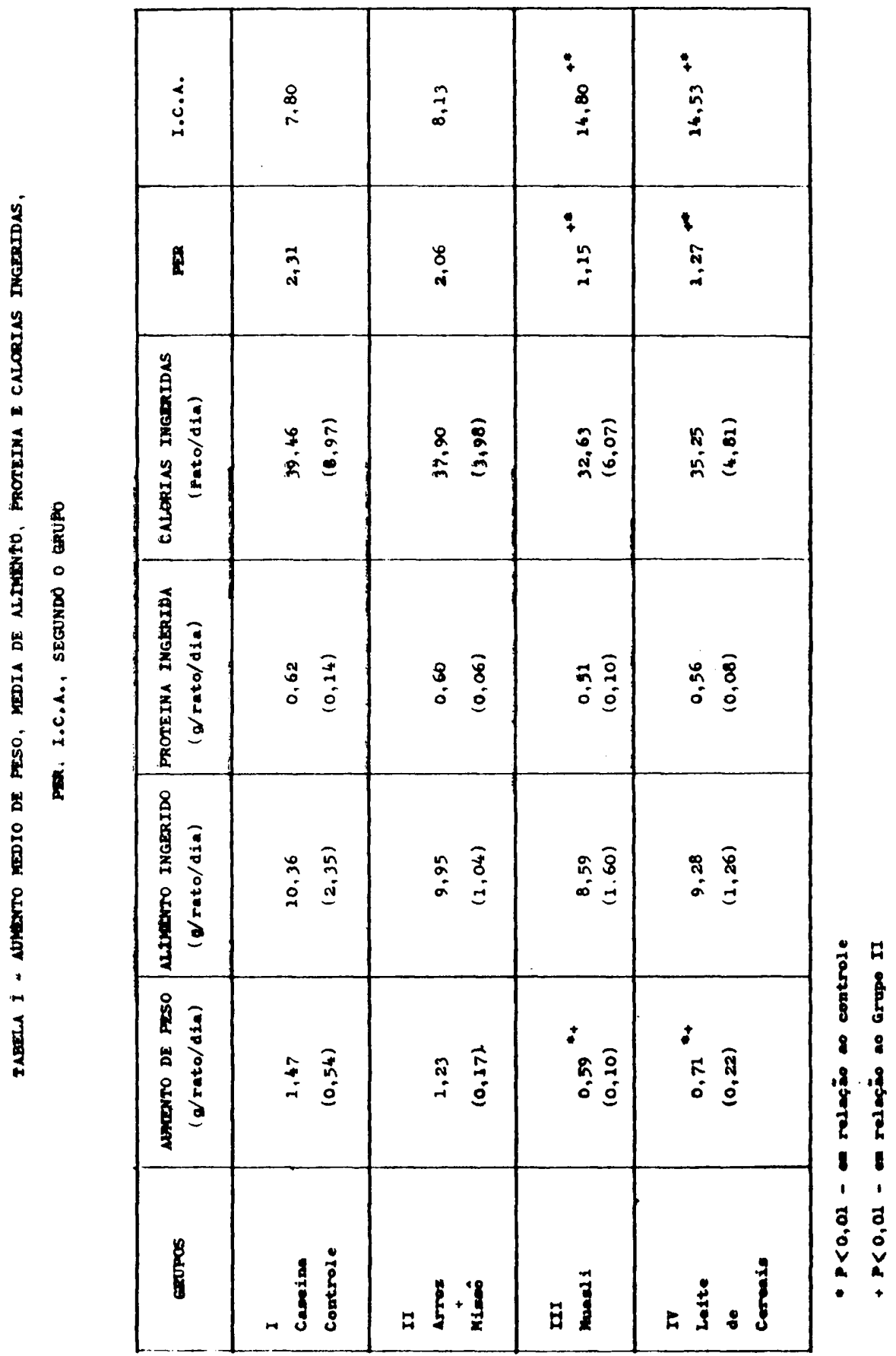




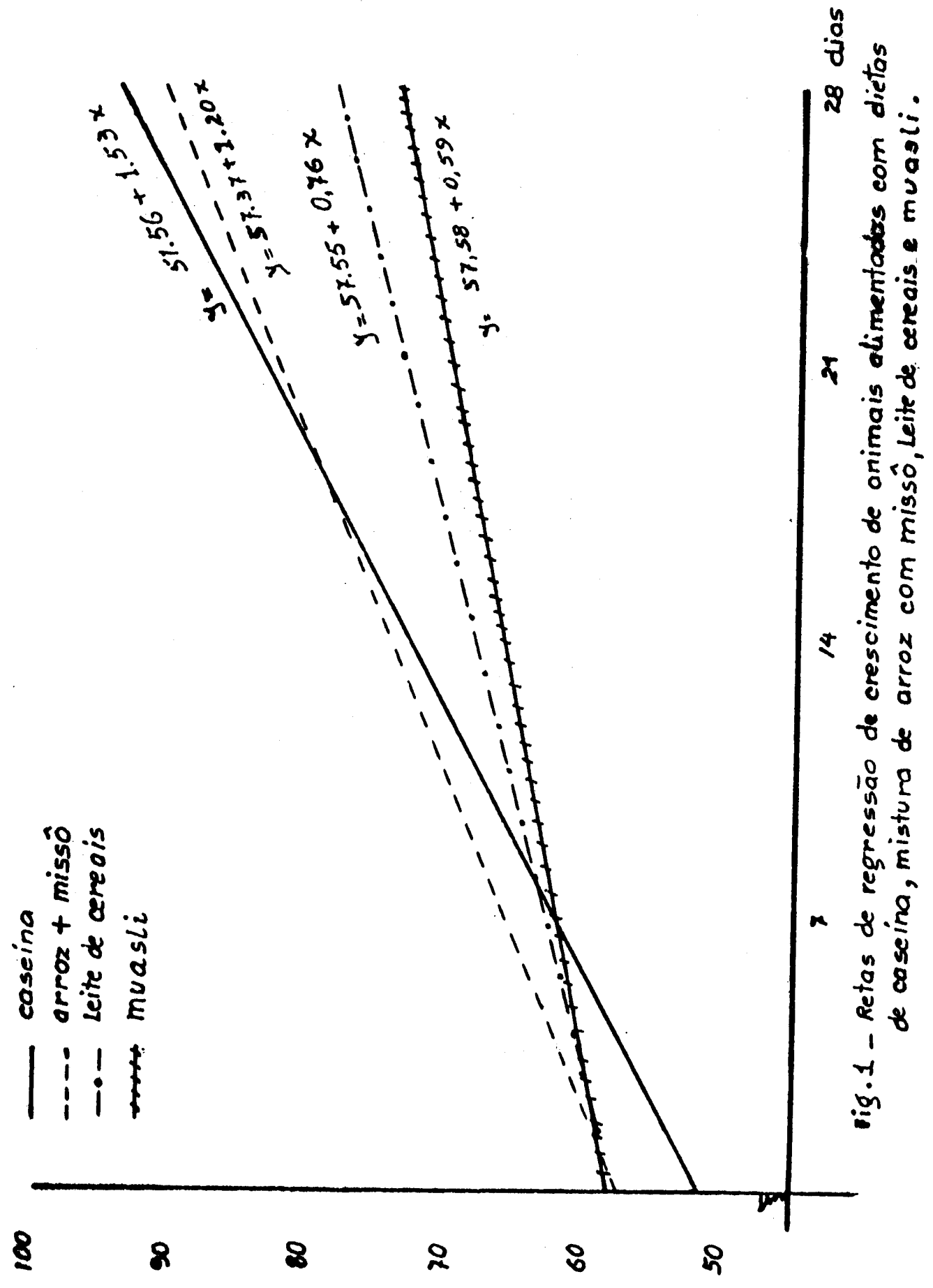

(8) osad 